\title{
Effects of Blade Tip Foil Thickening on Tip Vortexes in Ducted Propeller
}

\author{
Lei Mei ${ }^{a}$, Junwei Zhou ${ }^{*}$ b \\ School of Naval Architecture and Ocean Engineering, Harbin Institute of Technology in Weihai, \\ Weihai 264209, China \\ amlsmile81@163.com, bhou_junwei@foxmail.com,
}

Keywords: Tip clearance, tip leakage vortex, ducted propeller, foil thickening

Abstract. A thick tip foil blade was designed to reduce the tip leakage flow and weaken the tip vortexes in ducted propeller 19A/Ka4-55. The thick tip foil was constructed by normal extrusion of the original tip foil. The maximum thickness of the foil increased from $1.64 \%$ chord length to $7.64 \%$. The commercial CFD code CFX was employed to simulate the flow field of the two ducted propellers. From the performance curves, it could be concluded that the tip foil thickening will not affect the thrust and torque of the ducted propeller much. The tip leakage vortex (TLV) in the thick tip foil propeller was obviously weaker than that in the original propeller. The pressure drop in TLV middle chord position decreased by $32.8 \%$. In the tip clearance, both propellers have the tip clearance vortex. The difference is that the tip clearance vortex in the thick tip foil propeller could form an expansionary channel in the tip clearance, which made the tip leakage flow slow down, and hence weaken the TLV.

\section{Introduction}

Ducted propellers have significantly improved thrust and reduced noise compared to the traditional propeller[1-3], because the duct could produce extra thrust, absorb and isolate the noise. On account of the existence of the duct, there is a tip clearance between the duct inner wall and the blade tip foil. As the ducted propeller works, there will be severe tip leakage flow from the blade pressure side to suction side through the tip clearance[4]. The tip leakage flow induces tip leakage vortex, tip clearance vortex, trailing vortex and the secondary vortex[5-8], which may cause vortexes cavitation and noise[9-10].

To limit the harm caused by the tip vortexes and improve performance of the ducted propeller, the direct way is to weaken the tip vortexes. Since the tip vortexes are induced by the tip leakage flow, we can shorten the tip clearance $\delta$ to reduce the tip leakage flow, as shown in Fig. 1. This method has been proved to weaken the tip vortexes and raise the efficiency in our previous research and other studies[11-12]. But in the actual projects, there must be a certain size of the tip clearance to install the propeller rotor.

Focus on the shape of the tip clearance we can discover that the tip clearance is a rectangular channel, as shown in Fig. 1. It has a height of $\delta$ and a width of $\mathrm{t}$. As the size of the tip clearance $\delta$ decreases, the tip clearance ratio $\delta / t$ decreases. Since the narrow tip clearance channel benefits the performance of the ducted propeller, we can also reduce the $\delta / t$ by increasing the tip foil thickness $t$. This method is similar to the shroud blade in gas turbine[13].

In this article, we will attempt to reduce the tip leakage flow and weaken the tip vortexes in ducted propeller by the method of tip foil thickening.

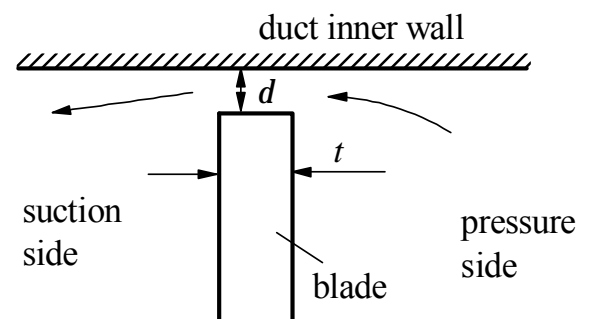

Fig. 1 The sketch of tip clearance shape and tip leakage flow 


\section{The ducted propeller}

This study will be performed on ducted propeller 19A/Ka4-55. The propeller has 4 blades and the blade area ratio is 0.55 . The full scaled propeller used in this research is designed to be equal pitch-to-diameter ratio of 0.963 , which is defined as

$$
P O D=\frac{\text { pitch }}{D} \text {. }
$$

The diameter $D$ of the model is $1.0 \mathrm{~m}$ and rotating speed $n$ is $20 \mathrm{rev} / \mathrm{s}$. The chord length and the skew angle of the blade were shown in Table 1, in which the $R$ is the radius of the blade, the $r$ is radius position, the $c$ is chord length and the skew is negative to the rotating direction. The coordinates of duct 19A was listed in Table 2, in which $L$ is duct length. The $y_{1}$ and $y_{2}$ in Table 1 mean Y coordinate on the outer and inner wall of the duct. The ratio of duct length to diameter $(L / D)$ is 0.5 .

Table 1 Design parameters of propeller Ka $4-55$

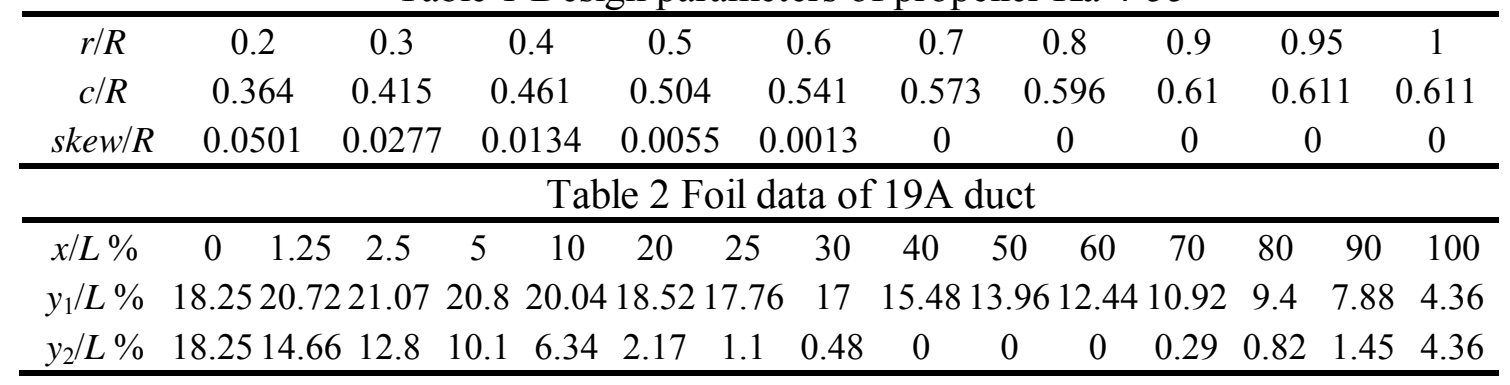

\section{Tip foil thicken}

From the Ka series propeller foils, there is

$t_{\text {tip }}=1.64 \% c_{\text {tip }}$.

The $t_{\text {tip }}$ is the maximum thickness of the tip foil and the $c_{t i p}$ is the chord length of the tip foil. Since $c_{\text {tip }}=0.611 R$, as listed in Table 1 , the $t_{\text {tip }}$ is about $1 \% R$.

In general, the tip clearance of a full scale propeller is less than $1 \%$ diameter. In this work, the tip clearance size $\delta$, as shown in Fig. 1 , is designed to be $0.4 \% D$, that is $0.8 \% R$. So, in the original ducted propeller, the tip clearance ratio

$$
\delta / t_{\text {tip }}=0.8 \text {. }
$$

To increase the thickness of the tip foil, the tip foil was normal extruded using hyperbolic extrusion method. The original tip foil and the extruded are shown in Fig.2. The maximum thickness of the extruded foil increases to $7.64 \% c_{t i p}$, and the tip clearance ratio decreases to $\delta / t_{\text {tip }}=0.171$.

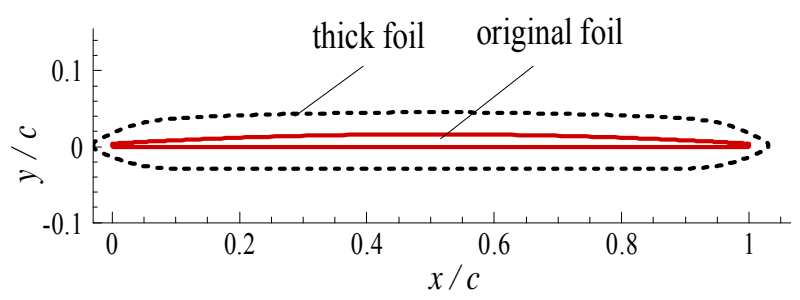

Fig. 2 Comparison of original tip foil and the extruded one

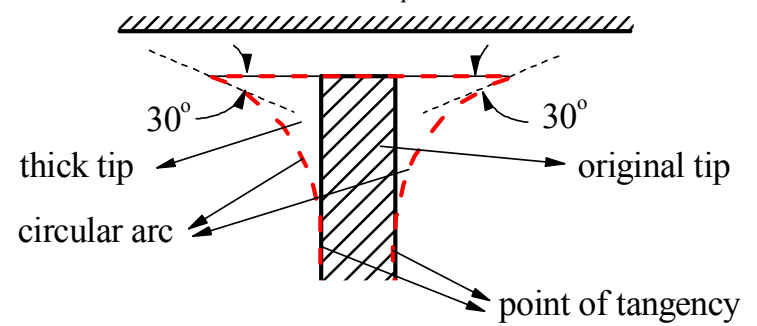

Fig. 3 Scheme of tip foil thickening method 


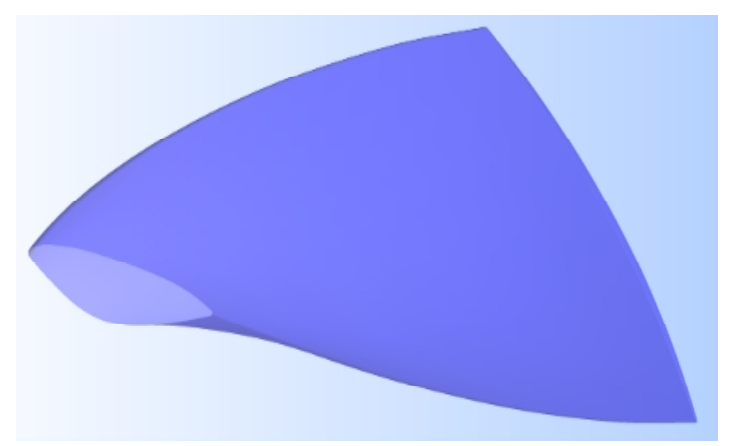

(a) original balde

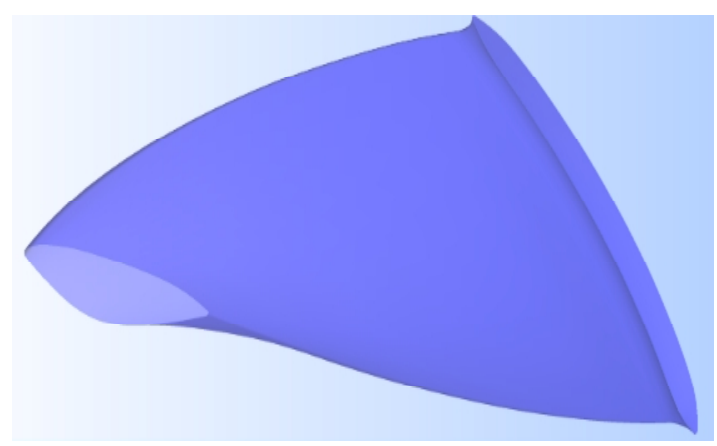

(b) thick tip foil blade

Fig. 4 3D view of the original blade and the thick tip foil blade

On the surface normal to tip foil chord direction, the shape comparison of the two blades is illustrated in Fig. 3, and the 3D models are shown in Fig.4. In the following, we will call the original ducted propeller as ORI propeller, and the thick tip foil ducted propeller as TTF propeller.

\section{Numerical method}

Reynolds-Averaged Navier-Stokes (RANS, for short) equations calculations are performed by the commercially available numerical code ANSYS-CFX ${ }^{[12,14]}$, which is based on the finite-volume method.

In order to save calculating time, only $1 / 4$ flow field of the propeller will be simulated. The entire flow field of the ducted propeller was divided into rotating region and stationary region, as showed in Fig. 5. The RANS equations were solved in the two regions respectively. The inlet boundary used normal velocity condition, and the static pressure outlet condition was set. The Rotor/Stator interface of the two regions was simulated by the Frozen Rotor boundary condition. Turbulence model $k-\varepsilon$ was used in the simulation and had been proved ${ }^{[12]}$ to be more suitable for the ducted propeller.

The rotating region was discretized by hexahedron grids, and the stationary region was filled with hybrid grids, as showed in Fig. 6 . The CFD method has been validated in the before ${ }^{[15]}$ and will not be repeated here.

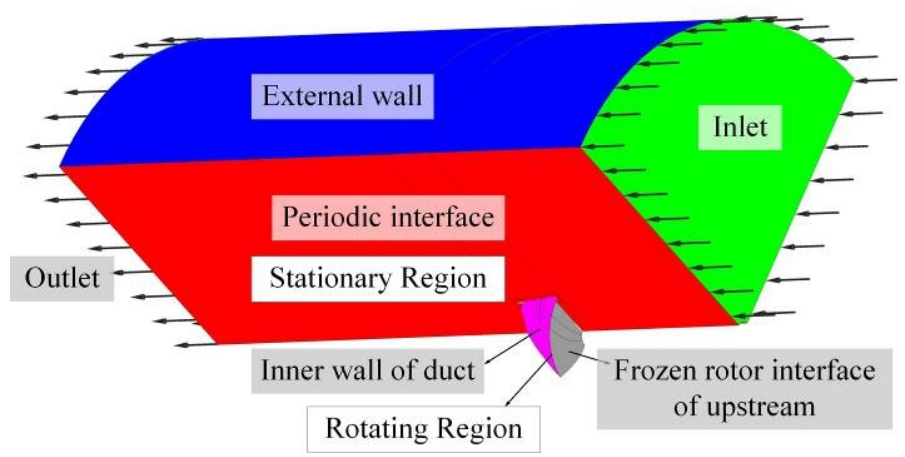

Fig. 5 Regions division and boundary conditions

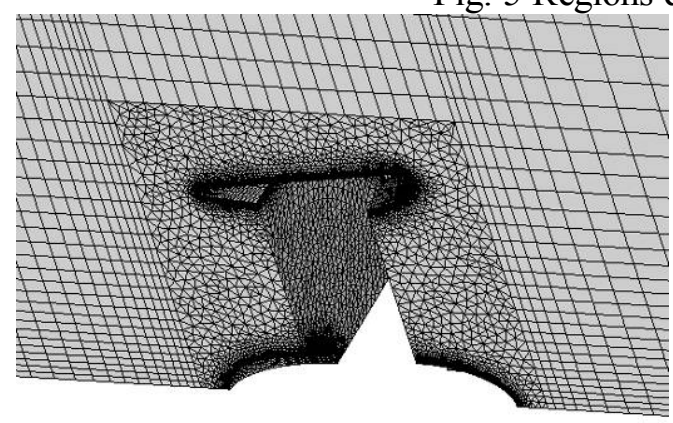

( a ) stationary region

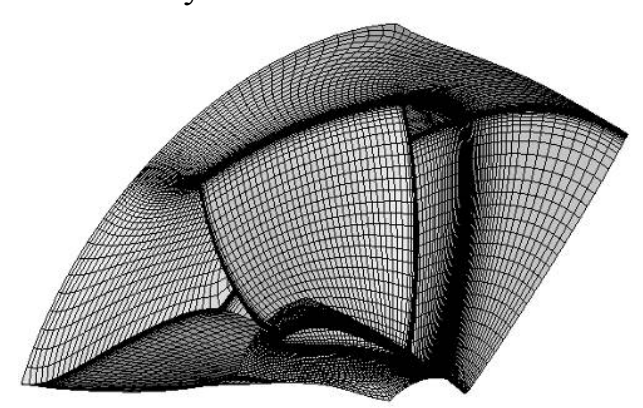

( b ) rotating region

Fig. 6 Meshes of the ducted propeller flow field. 


\section{Results and analysis}

Performance of the two ducted propellers. The performance parameters of the ducted propeller were defined as

$$
J=\frac{V_{A}}{n D}, K T=\frac{\text { Thrust }}{\rho n^{2} D^{4}}, K Q=\frac{\text { Torque }}{\rho n^{2} D^{5}}, \eta=\frac{J}{2 \pi} \frac{K T}{K Q} .
$$

in which the $V_{A}$ is inflow velocity.

The performance curves of both propellers were shown in Fig. 7. From $J=0.2$ to 0.8 , the thrust coefficient, torque coefficient and efficiency curves of the two propellers were almost the same. At the peak efficiency point of $J=0.65$, the efficiency of the TTF propeller is barely $0.8 \%$ lower than that of the ORI propeller.

In Fig. 8, the pressure contours on the suction sides of the two propellers at $J=0.5$ were plotted respectively. The pressure $p$ is relative to the far field. It could be seen that on the suction surface the pressure distribution does not change in most regions, and there is only some difference near the blade tip. That is why the thick tip foil barely affects performance of the ducted propeller.

Focus on the blade tip region, there are low pressure areas at leading and trailing edge on the TTF propeller, as shown in Fig. 9, which is different from the other one. Pay attention to the thick foil in Fig. 2 , we can notice that near leading edge and trailing edge, there are arcs of larger radius, which could cause larger areas of low pressure.

There is also a low pressure region near the middle of blade tip on the ORI propeller, as shown in Fig. 9 (a). As observed before ${ }^{[15]}$, the low pressure area was induced by the tip leakage vortex (TLV).

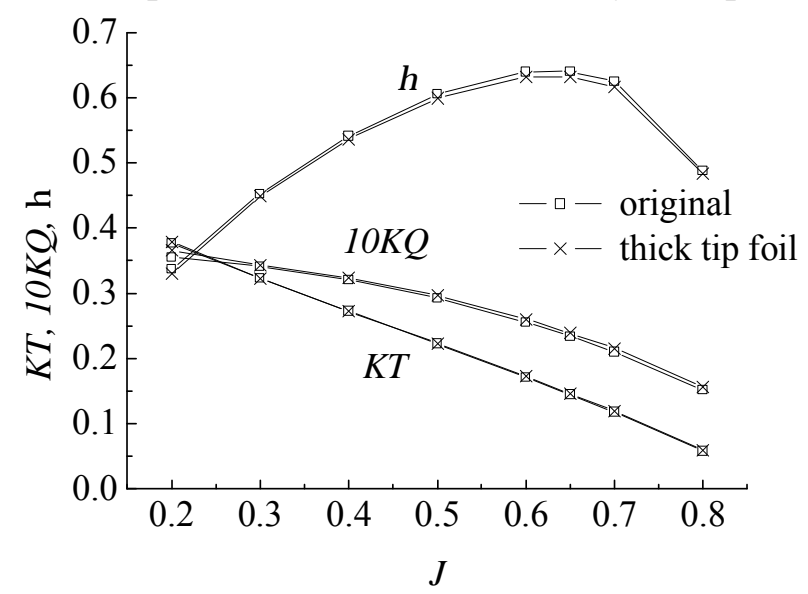

Fig. $7 K T, K Q$ and Efficiency curves of the two propellers by CFD

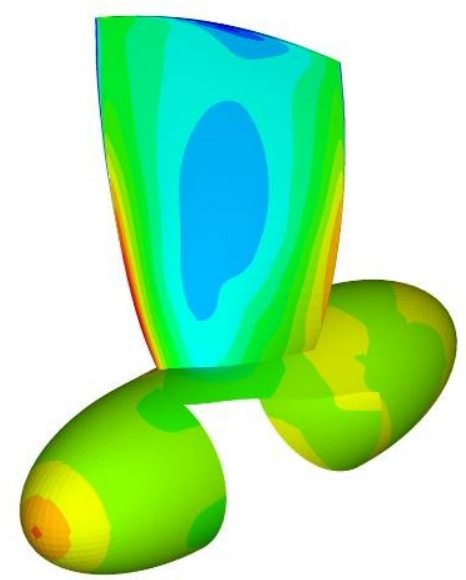

( a ) original propeller

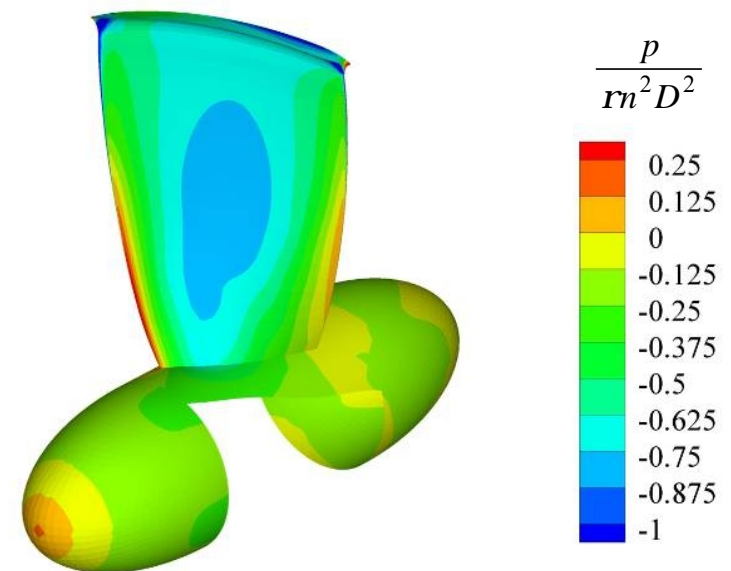

( b ) thick tip foil propeller

Fig. 8 pressure distribution of both propellers on blade and hub surface at $J=0.5$ 


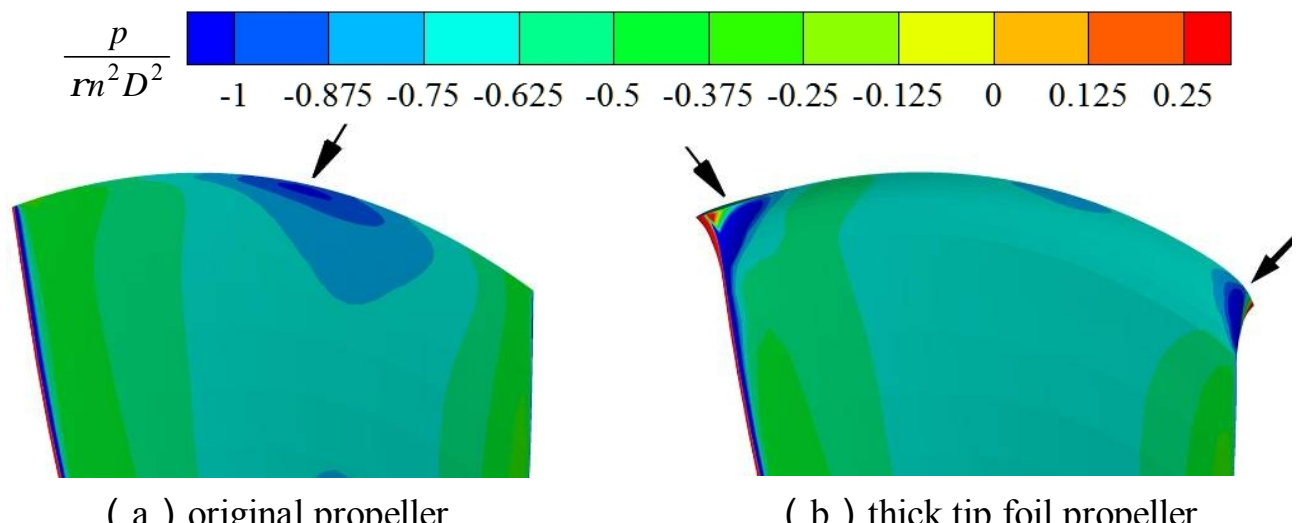

Fig. 9 pressure distribution of both propellers on blade and hub surface at $J=0.5$

The tip vortexes. As discovered in Storer's[6] and Hah's[7] researches, the tip vortexes in ducted propeller included the tip leakage vortex, the tip clearance vortex, the secondary vortex and the trailing vortex. In our previous study[15], we found that only the tip leakage vortex (TLV) and the tip clearance vortex are important in this ducted propeller (19A/Ka4-55).

Fig. 10 shows pressure on the slice surfaces normal to tip foil chord and the relative velocity streamline along the TLV at $J=0.3$. It is discovered that pressure in TLV of the TTF propeller is much lower than the pressure at the corresponding position of the ORI propeller, while the distance between the TLV and blade tip does not vary much. The tip clearance vortexes in the two propellers is difficult to express with streamline, and their pressure contour will be compared in the following.

The pressure contours and surfaces streamline of the slice $0 \#$ are plotted in Fig. 11. The low pressure areas at the suction side mean TLV core, that of the ORI propeller is $32.8 \%$ lower than that of the TTF propeller. Moreover, the TLV in the ORI propeller rolls up distinctly, but that in the TTF propeller is not clear. There is also vortexes in the pressure side of both propellers, which are still TLV but produced by the adjacent blade.

From the enlarged view of slice 0\# in Fig. 12, the area of low pressure region in the tip clearance of TTF propeller is larger than in the ORI propeller. Both of them have a tip clearance vortex on the blade tip. It is obvious that the tip clearance vortex is caused by the Coanda effect in the corner of tip foil pressure side, since the streamline near the blade tip from the pressure side to tip clearance takes a sudden turn and then rolls up to a tip clearance vortex. Although the thick tip foil has weakened the TLV, but it did not benefit the tip clearance vortex.

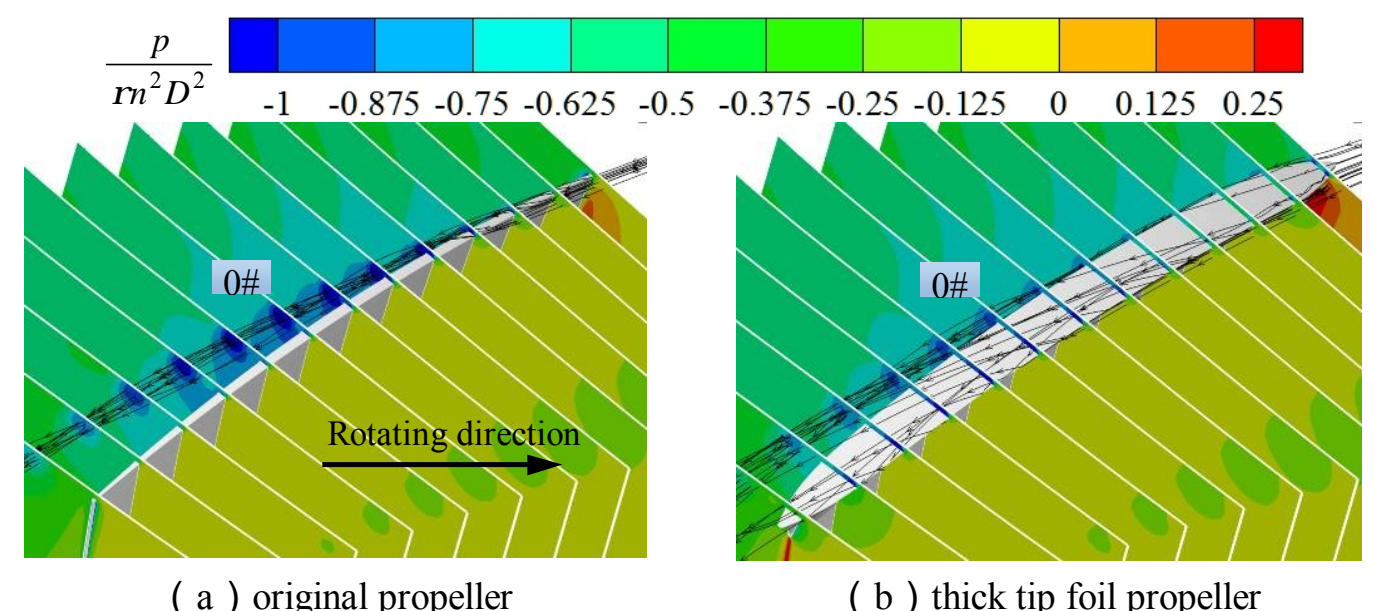

Fig. 10 Pressure and streamline of the two propellers near blade tip 


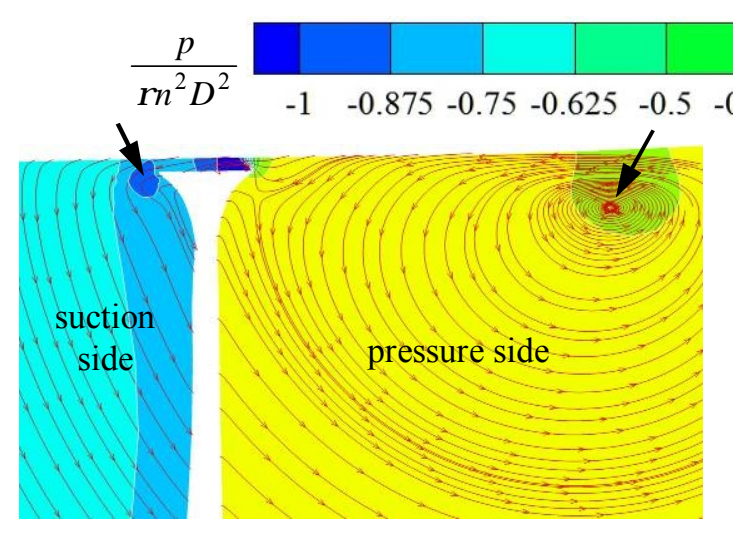

( a ) original propeller

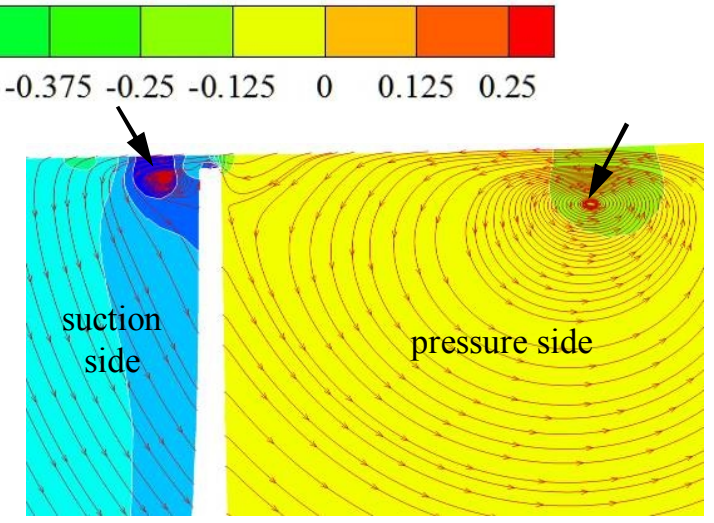

( b ) thick tip foil propeller

Fig. 11 Surface streamline on slice $0 \#$ and the pressure distribution near tip clearance

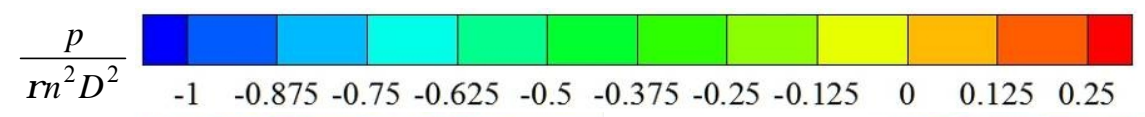

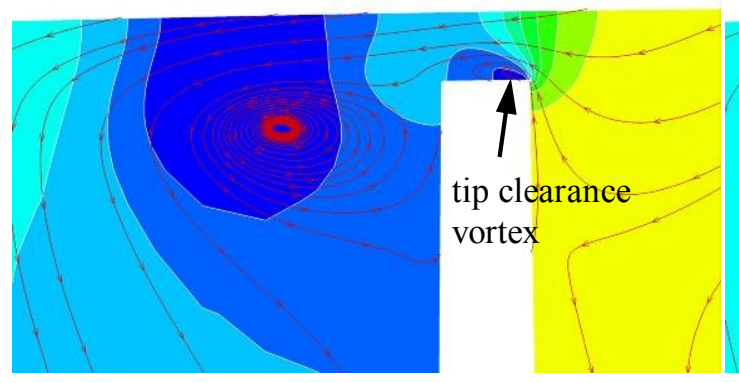

( a ) original propeller

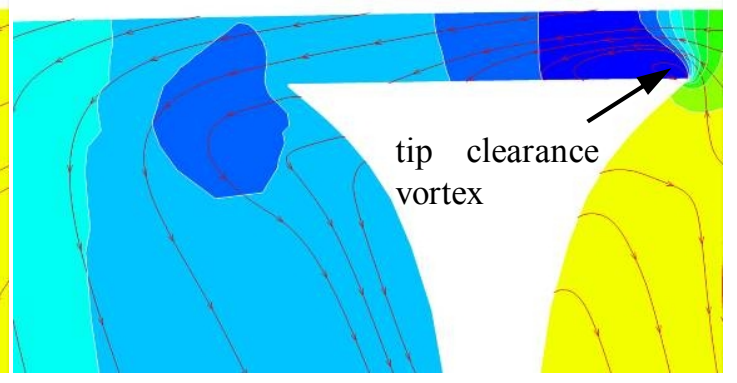

( b ) thick tip foil propeller

Fig. 12 Enlarged view of slice $0 \#$ near blade tip

The tip leakage flow. Why could the thick tip foil weaken the TLV? Since the TLV is relative to tip leakage flow, and it will be discussed in the following.

Setting the direction of $V_{\text {tip }}$ as shown in Fig.13, which is normal to the tip foil chord. This parameter means the velocity of the tip leakage flow. The $V_{t i p}$ is defined as

$$
V_{t i p}=V_{z} \cos \beta+V_{\theta} \sin \beta \text {. }
$$

in which the $V_{z}$ means the velocity of the inflow and the $V_{\theta}$ is along the rotating direction.

Nondimensionalized $V_{\text {tip }}$ by blade tip tangential velocity $\pi n D$, was shown in Fig. 14. The surfaces were still slice $0 \#$ at $J=0.3$. From Fig. 14 it can be discovered that the $V_{\text {tip }}$ of the TTF propeller is much lower than that of the ORI propeller at the outlet of tip clearance. Moreover, the maximum $V_{\text {tip }}$ of the TTF propeller in tip clearance was also lower than that of the ORI propeller.

Why does the TTF propeller have a lower $V_{\text {tip }}$ in the tip clearance? Obviously the effect of tip foil thickness is very important. The reasons may be in terms of two aspects.

Firstly, the thick tip foil increases the length of flow passage in tip clearance, and the viscosity of the wall may reduce the velocity of the tip leakage flow. But from Fig. 15 it could be seen that the boundary layer in tip clearances of the two propellers were not obvious, and so the effect of the viscosity can be neglected.

In another aspect, form Fig. 14, the comparison of the streamline in the tip clearances of the two propellers shows that, the tip clearance vortex decreases the inflow area of the tip leakage flow. In the TTF propeller, the tip leakage flow expands when passing through the tip clearance vortex, so its velocity decreases. While in the ORI propeller, there is no expansion process, since the length of the flow passage in tip clearance is very short. 


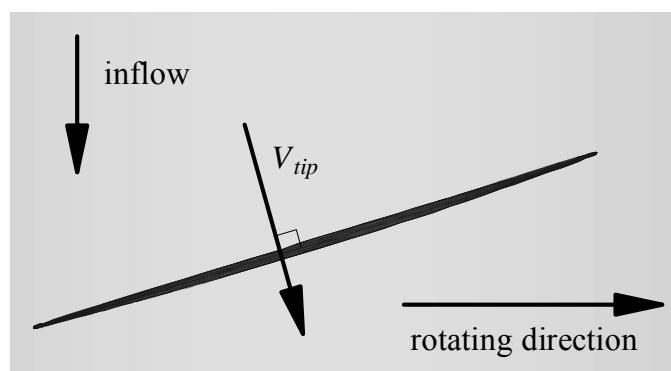

Fig. 13 The direction of the velocity of tip leakage flow $V_{t i p}$

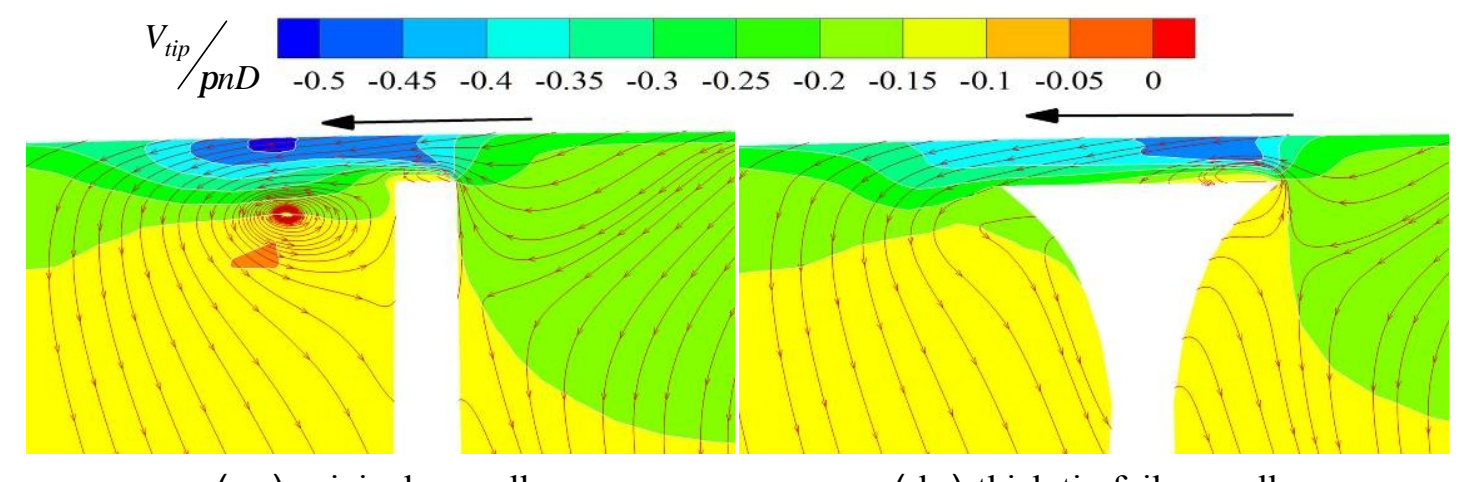

( a ) original propeller

( b ) thick tip foil propeller

Fig. 14 The contour of $V_{\text {tip }}$ surface of slice 0\# in the two propellers

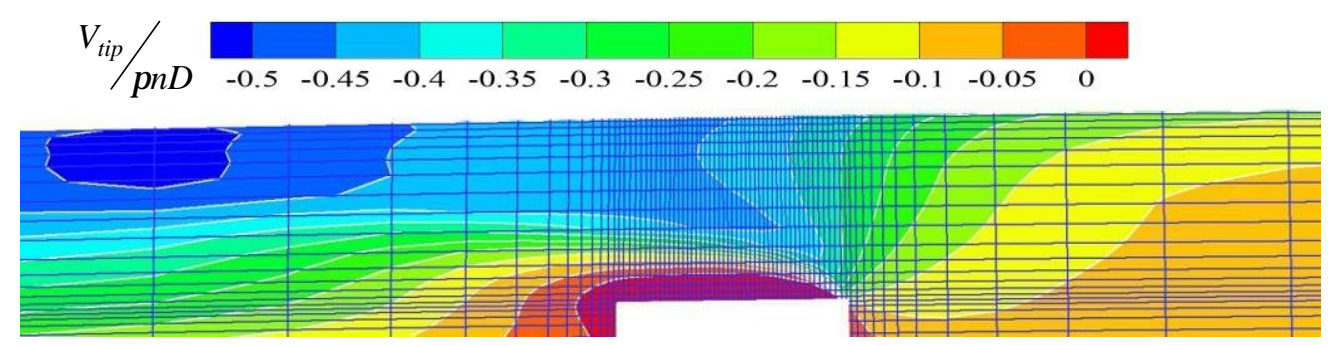

( a ) original propeller

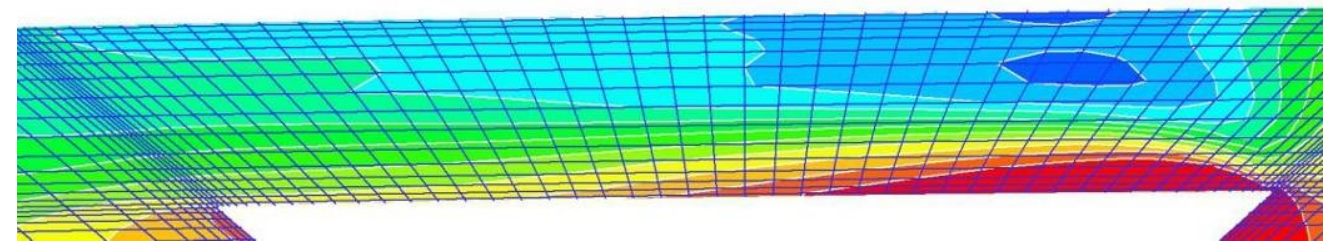

( b ) thick tip foil propeller

Fig. 15 Enlarged view of $V_{\text {tip }}$ contour with grid in the tip clearances of the two propellers

\section{Conclusion}

In this study, we attempted to weaken the tip vortexes by increasing the tip foil thickness in the ducted propeller. The studies were carried out on the ducted propeller 19A/Ka 4-55. The thickened tip foil has thickness of $7.64 \%$ chord length, compared with the original thickness of $1.64 \%$ chord length. The flow field of both ducted propellers was simulated by the commercial CFD code CFX. The results were summarized below.

1) The performance comparison indicated that the tip foil thickening barely changed efficiency and thrust of the propulsor.

2) The slice observation of tip flow showed that the thick tip foil propeller has less pressure drop in the TLV, which is about $32.8 \%$ less than the other one at middle chord position at $J=0.3$.

3) The comparison of the tip leakage flow in the two propellers revealed that, the velocity of the tip leakage flow in the thick tip foil is lower than that in the original propeller, so its TLV pressure drop is less. 


\section{Acknowledgements}

This work was supported by the National Natural Science Foundation(Grant No. 51309070), Shandong science and Technology Development fund (Grant No. 2013GGA10065), Harbin Institute of Technology scientific research innovation fund (Grant No. HIT.NSRIF.2013129) and Harbin Institute of Technology (Weihai) Dr. Startup funds (Grant No. HIT(WH)×201109).

\section{Reference}

[1] L. Kort, Nozzle Around Boat Propeller Adds to Powers, J. Popular Mechanics. (1937) 369.

[2] G.F. Oweis, D Fry, C.J. Chesnakas, Development of a Tip-Leakage Flow-Part 2: Comparison Between the Ducted and Un-ducted Rotor, J. Fluids Eng. 128(2006) 765-773.

[3] H. Seol, S. Pyo, J.C. Suh, S. Lee, Numerical study of non-cavitating underwater propeller noise, Noise \& vibration worldwide. 35(2004) 11-26.

[4] D.A Rains. Tip Clearance Flow in Axial Compressors and Pumps, California Institute of Technology, Hydrodynamics and Mechanical Engineering Laboratories Report No. 5, 1954.

[5] G.F Oweis, S. L Ceccio, Instantaneous and time-averaged flow fields of multiple vortices in the tip region of a ducted propulsor, Exp Fluids.38(2005) 615-636.

[6] J.A. Storer, N.A Cumpsty, Tip Leakage Flow in Axial Compressors, J TURBOMACH. 113 (1991) 252-259.

[7] C. Hah, Y.T. Lee, Unsteady Pressure Field Due To Interactions Among Tip Leakage Vortex, Trailing Edge Vortex, And Vortex Shedding In a Ducted Propeller, ASME Turbo Expo 2007,1639-1646.

[8] J.W. Zhou, A.P. Hou, S. Zhou, Effects of injection frequency on the rotor stall margin, SCIENCE CHINA Technological Sciences. 53(2010) 213-219.

[9] H. Wu, F. Soranna, T. Michael, Cavitation In The Tip Region Of The Rotor Blades Within a Waterjet Pump, ASME 2008 Fluids Engineering Division Summer Meeting, 193-202.

[10] W. H. Brewer, D. L. Marcum, S. D. Jessup, An Unstructured Rans Study Of Tip-Leakage Vortex Cavitation Inception, ASME/JSME 2003 4th Joint Fluids Summer Engineering Conference, 193-200.

[11]J. B. Li, CFD Analysis of Tip Clearance Effects on Duct Propeller's Performance, Ship \& Ocean Engineering. 39(2010) 36-39.(in Chinese)

[12]L. Yu, M. Greve, M. Druckenbrod, M. Abdel-Maksoud. Numerical analysis of ducted propeller performance under open water test condition, J Mar Sci Technol. 18(2013) 381-394.

[13]W. Jia, H.X. Liu. Loss Sources Analysis of Shroud Leakage Flow in Highly-Loaded Turbine, Tuijin Jishu/J. Propuls. Technol. 35(2014) 33-42.

[14]M. Miclea-Bleiziffera, A. Untaroiu, A. Delgado. Development of a novel design method for marine propellers by computing the exact lift of arbitrary hydrofoils in cascades, Ocean Eng. 83(2014) 87-98.

[15]J.W Zhou, D.Z. Wang, Analysis of tip leakage vortex of different blade in ducted propeller, J. Harbin Inst. Technol. (New Series), 46 (2014)14-19 
